\title{
Are Baseline Predictors of Death Different in Women with Acute Coronary Syndrome than in Men?
}

\author{
Trygve Sundby Hall \\ Division of Medicine, Oslo University Hospital, Oslo, Norway
}

Cardiovascular diseases are the leading causes of death, and among these, coronary artery disease (CAD) is the most prevalent entity [1]. Thus, investigating risk factors for mortality following an acute coronary syndrome (ACS) has been a focus of research for several decades. Particularly in the Western world, there has been considerable development in both treatment and prevention evidenced by an increased survival following ACS [2]. Nevertheless, there is still room for improvement; e.g., in particular subgroups of patients such as women and the elderly where knowledge gaps remain [3]. Hence, to improve the short- and long-term prognosis for both sexes, it remains a principal scientific task to better understand gender-related differences in patients with conditions such as ACS by identifying gender-specific risk factors. This may lead to personalized treatment, fine-tuned according to different patient profiles.

In this issue of Cardiology, Ravn-Fischer et al. [4] shed light on gender-specific differences on the prognosis after experiencing ACS by presenting extended follow-up data from the Prognosis and Risk (PRACSIS) Study. This study had a single-center design with consecutive inclusion of eligible patients with ACS admitted to a coronary care unit at one of Northern Europe's largest hospitals between 1995 and 2001 [5]. In the analysis by Ravn-

\section{KARGER}

() 2019 S. Karger AG, Basel

E-Mail karger@karger.com

www.karger.com/crd
Fischer et al. [4], the authors focused on the subjects who were still alive 30 days after their acute event $(n=2,176$ out of the total study sample of 2,335, of which 665 were women and 1,511 men). Survival confirmation or information on death was obtained from the national registry in Sweden up to the year 2015. Thus, the authors could quite comprehensively explore the risk of death associated with baseline characteristics among women and men.

The main findings of their report were that a higher proportion of women had died at the end of follow-up, but that the risk of mortality was lower when assessed in a model adjusted for age alone or for age and additional potential confounders. For gender-specific predictors of mortality, the authors found that previous heart failure, previous or new-onset atrial fibrillation, and use of psychotropic drugs at discharge were significantly associated with increased long-term mortality in men only, while known hypertension, elevated creatinine, and in-hospital Killip class $>1$ /cardiogenic shock were significantly associated with mortality only in women. Significant interaction with gender was demonstrated for two of the tested characteristics, namely hypertension and in-hospital Killip class $>1 /$ cardiogenic shock.

While it is perhaps not that surprising that the authors found different predictors for all-cause mortality in 
women and men after such a long follow-up, one might certainly be intrigued by the added knowledge this contributes to the topic of gender differences in CAD by and large. It remains an undisputed fact that ACS is associated with serious consequences, embodying a major clinical problem with significant implications for early and potentially avoidable morbidity and mortality $[1,2]$. For younger women in particular, the acute manifestation of $\mathrm{CAD}$; i.e., myocardial infarction, has historically been seen as an uncommon entity, but accumulating data support its increasingly recognized occurrence [6]. Moreover, myocardial infarction with nonobstructive coronary arteries is more common in women and, albeit not necessarily being associated with any evidenced CAD, it still carries a significant risk of adverse outcomes [7]. While most would agree that the traditional atherosclerotic CAD risk factors in many instances are involved in the potential progression to ACS for both genders, data suggest a greater role of microvascular disease in the pathophysiology of events among women $[8,9]$. Of note, women are usually older with a higher risk factor burden but paradoxically have less severe obstructive disease when investigated by angiography, and there may be differences in receiving and discontinuing guideline-recommended treatment $[10,11]$. Lastly, while women may or may not show different risk factor profiles and biological/phenotypical expressions, they most certainly often report different symptoms such as shortness of breath, nausea, and abdominal or arm pain when compared with male patients who classically present with chest pain [12]. To what degree these aforementioned observations relate and explain the findings of RavnFischer et al. [4] is difficult to assess, but it seems evident that potential gender-specific features should be carefully considered when diagnosing, treating, and risk-stratifying patients with ACS.

In conclusion, the authors should be commended for performing such a thorough analysis of predictors of long-term outcomes, representing yet another step forward in characterizing potential gender differences be- tween risk factors for death after ACS. The strengths of the study include the observational design representing real-life experience and the fact that the authors succeeded to obtain an impressive maximum follow-up of 19 years and 4 months. However, as they rightly imply under limitations, this long period invariably makes the explored associations more vulnerable to influence from competing risks and confounders. For example, it remains uncertain if the proportions of cancer deaths, which seemingly would be unrelated to several of the predictors that were tested, remained equally balanced between the groups throughout follow-up. Furthermore, the treatment of ACS and other competing risk conditions that may have an impact on all-cause mortality has changed substantially since these patients were included. Other key questions include whether the identified predictors represent markers only, or real causative pathophysiological factors, and to what degree the results are affected by only assessing the patients that had survived the first 30 days following their event. Nonetheless, this important and solid work supports the notion that significant gender differences between patients with ACS exist and reminds us of the likely remaining potential in developing improved, targeted, and more precise treatment for each individual ACS patient encountered on a daily basis in our clinical practice.

\section{Disclosure Statement}

Dr. Hall has consulted for or received honoraria from AstraZeneca, Bayer, Boehringer Ingelheim, Bristol-Myers Squibb, Imedic, Novartis, Sanofi, Siemens, and Pfizer, outside of the submitted work.

\section{Funding Sources}

No external funding was provided for producing the present paper.

\section{References}

1 World Health Organization. Noncommunicable diseases country profiles 2018. Geneva: World Health Organization; 2018.

2 Benjamin EJ, Muntner P, Alonso A, Bittencourt MS, Callaway CW, Carson AP, et al.; American Heart Association Council on Epidemiology and Prevention Statistics Committee and Stroke Statistics Subcommittee.
Heart Disease and Stroke Statistics-2019 Update: A Report From the American Heart Association. Circulation. 2019 Mar;139(10): e56-528.

3 Mehta LS, Beckie TM, DeVon HA, Grines CL, Krumholz HM, Johnson MN, et al.; American Heart Association Cardiovascular Disease in Women and Special Populations Committee of the Council on Clinical Cardiology, Council on Epidemiology and Prevention, Council on Cardiovascular and Stroke Nursing, and Council on Quality of Care and Outcomes Research. Acute Myocardial Infarction in Women: A Scientific Statement From the American Heart Association. Circulation. 2016 Mar; 133(9):916-47. 
4 Ravn-Fischer A, Perers E, Karlsson T, Caidahl K, Hartford M. 17-year mortality after acute coronary syndrome: gender-specific baseline variables and impact on outcome. Cardiology. DOI: $10.1159 / 000501166$.

5 Perers E, Caidahl K, Herlitz J, Sjölin M, Karlson BW, Karlsson T, et al. Spectrum of acute coronary syndromes: history and clinical presentation in relation to sex and age. Cardiology. 2004;102(2):67-76.

6 Arora S, Stouffer GA, Kucharska-Newton AM, Qamar A, Vaduganathan M, Pandey A, et al. Twenty Year Trends and Sex Differences in Young Adults Hospitalized With Acute Myocardial Infarction. Circulation. 2019 Feb; 139(8):1047-56.
7 Smilowitz NR, Mahajan AM, Roe MT, Hellkamp AS, Chiswell K, Gulati M, et al. Mortality of Myocardial Infarction by Sex, Age, and Obstructive Coronary Artery Disease Status in the ACTION Registry-GWTG (Acute Coronary Treatment and Intervention Outcomes Network Registry-Get With the Guidelines). Circ Cardiovasc Qual Outcomes. 2017 Dec;10(12):e003443.

8 Bairey Merz CN, Shaw LJ, Reis SE, Bittner V, Kelsey SF, Olson M, et al.; WISE Investigators. Insights from the NHLBI-Sponsored Women's Ischemia Syndrome Evaluation (WISE) Study: Part II: gender differences in presentation, diagnosis, and outcome with regard to gender-based pathophysiology of atherosclerosis and macrovascular and microvascular coronary disease. J Am Coll Cardiol. 2006 Feb;47(3 Suppl):S21-9.
9 Balla C, Pavasini R, Ferrari R. Treatment of Angina: Where Are We? Cardiology. 2018; 140(1):52-67.

10 Hvelplund A, Galatius S, Madsen M, Rasmussen JN, Rasmussen S, Madsen JK, et al. Women with acute coronary syndrome are less invasively examined and subsequently less treated than men. Eur Heart J. 2010 Mar; 31(6):684-90.

11 Bergmeijer TO, Janssen PW, van Oevelen M, van Rooijen D, Godschalk TC, Kelder JC, et al. Incidence and Causes for Early Ticagrelor Discontinuation: A "Real-World" Dutch Registry Experience. Cardiology. 2017;138(3):164-8.

12 Arslanian-Engoren C, Patel A, Fang J, Armstrong D, Kline-Rogers E, Duvernoy CS, et al. Symptoms of men and women presenting with acute coronary syndromes. Am J Cardiol. 2006 Nov;98(9):1177-81. 